\title{
Factors associated with frequency of abortions recorded through Dairy Herd Improvement test plans
}

\author{
H. D. Norman, ${ }^{\star 1}$ R. H. Miller, ${ }^{\star}$ J. R. Wright, ${ }^{*}$ J. L. Hutchison, ${ }^{*}$ and K. M. Olson ${ }^{2}$ \\ ${ }^{*}$ Animal Improvement Programs Laboratory, Agricultural Research Service, USDA, Beltsville, MD 20705-2350 \\ †National Association of Animal Breeders, Columbia, MO 65205
}

\begin{abstract}
Frequency of abortions recorded through Dairy Herd Improvement (DHI) testing was summarized for cows with lactations completed from 2001 through 2009. For 8.5 million DHI lactations of cows that had recorded breeding dates and were $>151 \mathrm{~d}$ pregnant at lactation termination, the frequency of recorded abortions was $1.31 \%$. Effects of year, herd-year, month, and pregnancy stage at lactation termination; parity; breed; milk yield; herd size; geographic region; and state within region associated with DHI-recorded abortion were examined. Abortions recorded through DHI (minimum gestation of $152 \mathrm{~d}$ required) were more frequent during early gestation; least squares means (LSM) were 4.38, $3.27,1.19$, and $0.59 \%$ for 152 to 175,176 to 200,201 to 225 , and 226 to $250 \mathrm{~d}$ pregnant, respectively. Frequency of DHI-recorded abortions was $1.40 \%$ for parity 1 and $1.01 \%$ for parity $\geq 8$. Abortion frequency was highest from May through August (1.42 to 1.53\%) and lowest from October through February (1.09 to 1.21\%). Frequency of DHI-recorded abortions was higher for Holsteins $(1.32 \%)$ than for Jerseys $(1.10 \%)$ and other breeds $(1.27 \%)$. Little relationship was found between DHI-recorded abortions and herd size. Abortion frequencies for effects should be considered to be underestimated because many abortions, especially those caused by genetic recessives, go undetected. Therefore, various nonreturn rates (NRR; 60, 80, .., $200 \mathrm{~d}$ ) were calculated to document pregnancy loss confirmed by the absence of homozygotes in the population. Breeding records for April 2011 US Department of Agriculture sire conception rate evaluations were analyzed with the model used for official evaluations with the addition of an interaction between carrier status of the service sire (embryo's sire) and cow sire (embryo's maternal
\end{abstract}

\footnotetext{
Received September 29, 2011.

Accepted February 29, 2012.

${ }^{1}$ Corresponding author: Duane.Norman@ars.usda.gov

${ }^{2}$ Current address: ABS Global Inc., 1525 River Rd., DeForest, WI
} 53532 . grandsire). Over 13 million matings were examined using various NRR for Holstein lethal recessive traits (brachyspina and complex vertebral malformation) and undesirable recessive haplotypes ( $\mathrm{HH} 1, \mathrm{HH} 2$, and HH3) as well as $>61,000$ matings for a Brown Swiss haplotype (BH1), and 670,000 matings for a Jersey haplotype (JH1). Over $80 \%$ of fertility loss occurred by $60 \mathrm{~d}$ after breeding for BH1, HH3, and JH1, by $80 \mathrm{~d}$ for HH2, by $100 \mathrm{~d}$ for BY, and by $180 \mathrm{~d}$ for HH1. For complex vertebral malformation, fertility loss increased from 40 to $74 \%$ across gestation. Association of undesirable recessives with DHI-recorded abortions ranged from $0.0 \%$ for Jerseys to $2.4 \%$ for Holsteins.

Key words: abortion, conception rate, haplotype, nonreturn rate

\section{INTRODUCTION}

Abortions cause significant economic loss, especially those occurring during late gestation. Estimates of the cost of an abortion to a producer range from $\$ 90$ to $\$ 1,900$ (Peter, 2000; Kirk, 2003; De Vries, 2006; Hovingh, 2009), depending on when during pregnancy the abortion occurred and differences in predicted cow performance, prices, and breeding and replacement decisions. Hanson et al. (2003) stated that losses were $\$ 200$ million per year in California herds.

Hovingh (2009) listed numerous causes of abortion: infectious agents (bacteria, viruses, protozoa, and fungi), toxic agents, heat stress, and genetic abnormalities. Twin pregnancies (Nielen et al., 1989) and mastitis (Risco et al., 1999; Santos et al., 2003) have also been implicated. Infectious agents are the most commonly diagnosed cause. Jamaluddin et al. (1996) examined 595 abortion submissions in California and found that infectious agents accounted for $37.1 \%$; noninfectious agents, $5.5 \%$; and undetermined causes, $57.3 \%$. Among the $37.1 \%$ due to infectious agents, bacteria accounted for $18.0 \%$; protozoa, $14.6 \%$; viruses, $3.2 \%$; and fungi, 1.3\%. In Canada, Khodakaram-Tafti and Ikede (2005) indicated that the 3 most common identifiable infectious agents were bacterial (24\%), fungal (7\%), and viral $(6 \%)$. 
Several recessives detrimental to reproductive performance have been confirmed and documented for several dairy breeds. An example of a genetic abnormality that causes abortion is the complex vertebral malformation (CVM) gene in Holsteins (Agerholm et al., 2001). The CVM gene causes malformations in middle to late gestation, although a few pregnancies reach term and result in stillbirths. A program to reduce the number of bulls that carry this recessive allele was established in the United States (Sattler, 2002) and has virtually eliminated bulls marketed by US AI organizations as a source of perpetuating the recessive allele in the US Holstein population.

Recently, Holstein Association USA (2011) added brachyspina (BY; Agerholm and Peperkamp, 2007) to its list of undesirable recessive traits after VanRaden et al. (2011b) confirmed inheritance through a lack of homozygous haplotypes in the population and reduced reproductive success when BY carriers were present both in the service sire and cow sire. VanRaden et al. (2011b) also searched the entire genome for similar haplotypes that had no homozygotes and discovered 5 new recessives that were confirmed to have either blocked conception or produced termination of any resulting pregnancy: 3 in the Holstein breed (HH1, HH2, and HH3) and 1 each in the Jersey (JH1) and Brown Swiss (BH1) breeds. An examination of the effects of those 5 haplotypes on fertility showed that BH1, JH1, $\mathrm{HH} 2$, and HH3 produced embryo losses soon after conception, but HH1 resulted in uniform losses across the entire gestation (VanRaden et al., 2011a). All of those recessives are responsible for pregnancy losses, most of which go undetected and thus are not included in any method of reporting abortions.

Several reports are available on abortion frequency in the United States but no national surveys. Hovingh (2009) stated that a fetal loss of 3 to $5 \%$ per year $(>42$ d of gestation) is expected, whereas Kirk (2003) estimated a 2 to $5 \%$ loss. Forar et al. (1996) reported $10.8 \%$ fetal loss between 31 and $260 \mathrm{~d}$ of gestation in 10 Holstein herds in the northwestern United States. Carpenter et al. (2006) reported a 1.5\% frequency of abortion in 507 Danish herds. Moller et al. (1967) reported an abortion rate of $1.2 \%$ in 200 New Zealand dairy herds. Murray (1990) found an annual abortion frequency of 2\% among 3,600 cows in England. A review by Forar et al. (1995) found that fetal loss reported in the literature ranged from 0.4 to $10.6 \%$. Few studies describe differences in frequency among years, seasons, parities, or pregnancy stages. Carpenter et al. (2006) reported that abortions in July were nearly twice the mean frequency expected had they occurred randomly. Pitel et al. (2001) found that Neospora-associated abortions peaked during summer.
Fetal loss is less likely to be detected in earlier stages of pregnancy than in later pregnancy. Hovingh (2009) indicated that careful observation of animals should help in detecting abortions as they occur. In a study by Kinsel (1999), only 1,380 of 3,012 abortions (46\%) were detected. Forar et al. (1996) reported that only $20 \%$ of fetal losses were detected by observation of expelled fetal membranes between 31 and $260 \mathrm{~d}$ of gestation. Based on those 2 studies, the number of actual abortions may be from 2.2 to 5.0 times the number of observed abortions. Ettema and Santos (2004) found a frequency of fetal loss of $9.8 \%$ in 3 California herds. Thurmond et al. (1990a) found an 11\% frequency of abortion in 3 California herds, but no fetal evidence was recovered. The difficulty in observing physical evidence of early abortion is probably why the DHI definition for a lactation that ends in abortion sets 152 $\mathrm{d}$ of gestation as a minimum. That recording guideline has been used in DHI for many years (American Dairy Science Association, 1941). Norman et al. (2009) provided a comprehensive examination (25 measures) of the reproductive status of Holstein and Jersey cows in the United States over 11 yr. Their results reflected but did not reveal any of the physiological causes that affect reproductive performance.

The objective of this study was to determine which factors affect the frequency of DHI-recorded abortions. The factors examined were year, herd-year, month, parity, pregnancy stage, breed, herd size, milk yield, region, and state within region. Factors that contribute to DHI-recorded abortions were assumed to be the same as those that affect the actual occurrence of abortions. In addition, an effort was made to define more closely when fertility is affected negatively by BY and CVM in the Holstein breed and by 5 recently discovered undesirable haplotypes in the Holstein, Jersey, and Brown Swiss breeds. The possible contribution of those undesirable recessives to DHI-recorded abortion rate also was examined.

\section{MATERIALS AND METHODS}

Using data from the national dairy database maintained by the Animal Improvement Programs Laboratory, Agriculture Research Service, US Department of Agriculture (Beltsville, MD), termination codes for lactations that ended during 2001 through 2009 were examined. Lactations that ended $<1$ yr before the herd's last recorded test and lactations without estimates of 305-d mature-equivalent milk yield were excluded. Incidence of recorded abortions was based on a lactation termination code of 8 , which is defined as "lactation ended with an abortion at $\geq 152 \mathrm{~d}$ and $\leq 250 \mathrm{~d}$ ( $\leq 260 \mathrm{~d}$ for Brown Swiss) after conception, 
Table 1. Comparison of size of effects estimated from sample ${ }^{1}$ and full data sets ${ }^{2}$

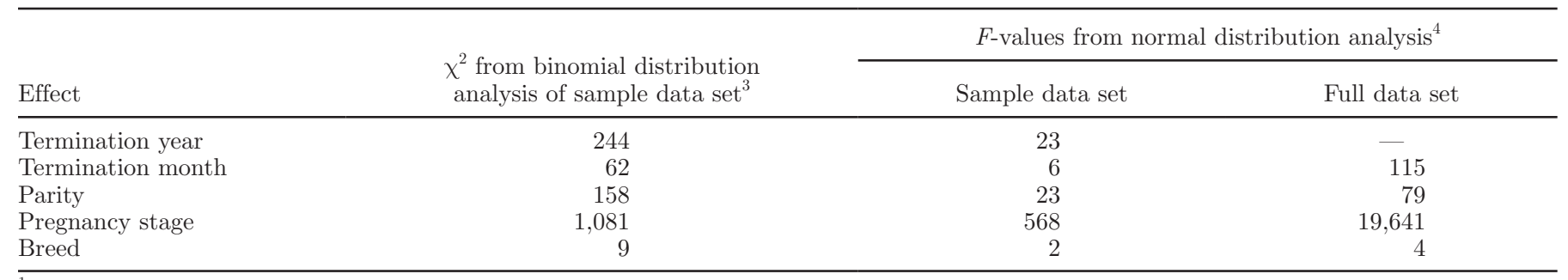

${ }^{1}$ Sample data set based on 759,394 lactations and 483 herds in DHI testing; all effects significant $(P<0.01)$ except for breed.

${ }^{2}$ Complete data set based on 8,496,291 lactations and 10,426 herds in DHI testing; all effects significant $(P<0.001)$.

${ }^{3}$ PROC GENMOD used for binomial distribution (SAS Institute, 2004).

${ }^{4}$ PROC GLM used for normal distribution (SAS Institute, 2004).

or aborted at $\geq 200$ DIM if no breeding date" (Animal Improvement Programs Laboratory, 2011a). Fetrow et al. (2006) listed several alternatives for expressing culling incidence, such as frequency per cow-year, per cow-month, or per lactation. Frequency of recorded abortions was expressed as the probability of incidence during a lactation; that is, recordings were binomial (0 $=$ no abortion and $1=$ abortion).

Pregnancy stage at lactation termination was calculated as the interval from last insemination (based on last recorded service date) to last day milked (based on DIM). Only lactations from pregnant cows were included (records with $<152$ or $>250$ d pregnant were excluded). Records with $<152 \mathrm{~d}$ pregnant at lactation termination were not included because of DHI data collection procedures that specify that "if a cow aborts while in milk and has carried a calf less than $152 \mathrm{~d}$, her current record will continue without interruption" (National DHIA, 2002). Records with $>250 \mathrm{~d}$ pregnant were not included because the short days open indicated that the breeding date likely was recorded erroneously. Lactations without supporting breeding dates were not used.

Risk of abortion was derived for pregnancy stage and for lactation stage. Risk was defined as the probability that a milking cow (one that had not aborted during the lactation) would abort on each specified day.

Preliminary analyses were done with a sample of 759,394 lactations from 483 herds, which were chosen based on the unit position of the herd code. Two analyses were compared: PROC GENMOD for binomial distributions and PROC GLM for normal distributions (SAS Institute, 2004). Because GENMOD failed to converge if herds with no recorded abortions were included, herds with an abortion frequency of $<0.1 \%$ were excluded from both analyses. An additional restriction excluded herds with $<500$ lactations across all years to permit processing with the software package. No attempt was made to eliminate herds simply for deficient reporting. The model for the preliminary analyses included effects for herd, year and month of lactation termination, parity $(1,2, \ldots, 7, \geq 8)$, pregnancy stage at lactation termination $(152-175,176-200,201-225$, and 226-250 d), and cow breed (Holstein, Jersey, or other). Crossbreds were included in the category for other breeds.

Table 1 compares variance analysis results from GENMOD and GLM for the 483 sample herds. The 2 methods ranked the contribution of the model effects similarly for both samples: pregnancy stage was most important followed by termination year, parity, termination month, and finally breed. All effects were significant $(P<0.01)$ in both analyses except breed.

For the full data set, the minimum frequency for recorded abortions $(<0.1 \%)$ was eliminated (i.e., all herds were included), and the restriction on the number of lactations per herd was reduced from $\geq 500$ to $\geq 50$. Herds with a mean gestation length that differed by more than $3 \mathrm{~d}$ from breed mean for the period 2001-2005 and 2006-2009 or for the entire period (2001-2009) were excluded because they were considered to have unreliable breeding data. The full data set after editing included records for 8,496,291 lactations of pregnant cows in 10,426 DHI herds with reported breeding dates.

The full data set was analyzed with almost the same model as that for the preliminary analyses and GLM because GLM and GENMOD results had been similar for the preliminary analyses and GENMOD required an excessive amount of computer resources. For the full data set, herd-year effects were combined and removed by absorption, and an effect was added for standardized lactation milk yield within herd based on 3 levels (high $20 \%$, medium $60 \%$, and low 20\%). All model effects were significant $(P<0.001)$. Yield records from the national dairy database are standardized for calving age, calving month, milking frequency, lactation length, and previous days open (Schutz, 1994). A secondary analysis of herd-year means included effects of region (Mideast, Midwest, Mountain-Prairie, Northeast, Northwest, Southeast, and Southwest) as defined by 
Hare et al. (2004), state within region, and herd size (50-100, 101-200, 201-400, 401-700, 701-1,000, and $\geq$ 1,001 cows).

Phenotypic frequencies and LSM were also derived with the effect of lactation stage added to the model to show its joint distribution with pregnancy stage when abortions occurred. Lactation stage was defined by DIM groups of $<250,250-349,350-449,450-549$, and 550-999 d; pregnancy stages were the same as for prior analyses.

Because some abortions are caused by genetic factors, pregnancy terminations resulting in the shortage or absence of homozygotes for BH1, HH1, HH2, HH3, JH1, BY, and CVM in the population were examined to determine more closely when fetal losses occurred. Breeding records were analyzed using April 2011 data for official USDA phenotypic evaluations for sire conception rate (SCR). The model for USDA SCR evaluations includes covariances for inbreeding levels of service sire and embryo and random effects for age of the service sire, AI organization of the service sire combined with mating year, and the bull as well; in addition, 8 nuisance variables associated with the cow that is being serviced are included to improve predictions of service sire fertility (Kuhn and Hutchison, 2008; Norman et al., 2008). An interaction for recessive carrier status of the service sire (sire of the embryo or newborn calf) with carrier status of the cow sire (maternal grandsire of the embryo) was added to the official model.

Each bull was assigned to 1 of 3 carrier statuses (genotype untested, noncarrier, or carrier) for each recessive examined. When carrier statuses of service sire and cow sire for each individual mating were examined together, they represented 9 possible combinations. Those 9 combinations were reduced to 3 groups: animals with both a carrier service sire and carrier sire, animals with a noncarrier service sire, and all other carrier status combinations. Solutions were obtained using BLUPF90 programs (Misztal, 2011). Differences between animals with a carrier service sire and carrier sire, which were the animals with the highest probability $(12.5 \%)$ of having a lethal defect, and animals with a noncarrier service sire, which were the only animals with no possibility of having a lethal defect other than from a mutation, were calculated. Differences between other carrier status groups also were calculated but not reported because of the intermediate and varying likelihoods of producing a lethal defect (in some cases because the maternal granddam was a carrier). Standard errors for carrier status differences were calculated using PROC GLM (SAS Institute, 2004).

To estimate the time of embryo loss (undetected abortion) during gestation for each carrier status com- bination, SCR differences were compared with carrier status differences for various nonreturn rates (NRR; $60,80, \ldots, 200 \mathrm{~d}$ ), which were calculated using a model that included the same variables as for SCR. Information such as subsequent breeding, subsequent estrus, or a pregnancy check designated as open was used to code conception outcome for NRR: failure (0) or success (1). As an indicator of fertility, SCR was assumed to be more accurate than NRR because SCR includes information only from confirmed breedings, and an abortion is considered to result in a nonpregnant cow. Time of embryo loss during gestation was determined by dividing the carrier status difference for each NRR by the carrier status difference for SCR.

To determine the extent to which the undesirable recessives were associated with the abortion rate recorded through DHI, frequency of animals that were heterozygous (carriers) for each recessive was examined within each breed. Expected fertility loss from random mating of carriers was calculated as 0.25 times the square of carrier frequency. Expected fertility loss from 150 to $250 \mathrm{~d}$ pregnant was based on the estimated time of embryo loss during gestation. The likelihood that a random mating would result in fertility loss from 150 to $250 \mathrm{~d}$ pregnant was calculated and multiplied times breed LSM for DHI-recorded abortions to determine the maximum percentage of abortions that might be associated with the undesirable recessives.

\section{RESULTS AND DISCUSSION}

Numbers of lactations, phenotypic means, and LSM for frequency of DHI-recorded abortions are shown in Table 2 by lactation termination month for the full data set. Overall frequency of DHI-recorded abortions was $1.31 \%$. Phenotypic means varied from $1.10 \%$ in December to $1.46 \%$ in July. The spread in LSM (0.44 percentage points) was similar to that for phenotypic means ( 0.36 percentage points). All but 5 of the 66 LSM differences between calendar months were significant $(P<0.05)$. Two seasonal groups for DHI-recorded abortions were apparent: high (April through August) and low (September through March), but the reason for the seasonal difference is unknown. However, both temperature and humidity likely affect the spread of contagious agents. European studies (Pitel et al., 2001; Carpenter et al., 2006) also reported highest abortion frequencies in summer.

Phenotypic means for frequency of DHI-recorded abortions (Table 3 ) ranged from $1.25 \%$ for parity $\geq 8$ and $1.26 \%$ for parity 1 to $1.41 \%$ for parities 4,5 , and 6 . The difference between highest and lowest LSM for parities (Table 3 ) was more pronounced (0.39 percent- 
Table 2. Numbers of lactations, phenotypic means, and LSM of frequency of DHI-recorded abortions by month in which lactation terminated

\begin{tabular}{lccc}
\hline $\begin{array}{l}\text { Month of lactation } \\
\text { termination }\end{array}$ & $\begin{array}{c}\text { Lactations, } \\
\text { no. }\end{array}$ & $\begin{array}{c}\text { Phenotypic } \\
\text { mean, \% }\end{array}$ & LSM, ${ }^{1} \%$ \\
\hline January & 578,595 & 1.15 & 1.17 \\
February & 487,887 & 1.28 & 1.20 \\
March & 549,492 & 1.42 & 1.27 \\
April & 626,953 & 1.44 & 1.36 \\
May & 734,634 & 1.40 & 1.42 \\
June & 771,016 & 1.41 & 1.47 \\
July & 825,888 & 1.46 & 1.53 \\
August & 816,550 & 1.37 & 1.42 \\
September & 795,308 & 1.30 & 1.30 \\
October & 820,518 & 1.21 & 1.21 \\
November & 749,538 & 1.14 & 1.14 \\
December & 739,912 & 1.10 & 1.09 \\
All months & $8,496,291$ & 1.31 & 1.31 \\
\hline
\end{tabular}

${ }^{1}$ All months were significantly different $(P<0.05)$ except for January and February, January and November, February and October, March and September, and May and August.

age points) than for phenotypic means ( 0.16 percentage points). The LSM for abortion frequency was highest for parity 1 (1.40\%), ranged from 1.21 to $1.29 \%$ for parities 2 through 6 , and was lowest (1.01\%) for parity $\geq 8$. Younger cows may have less acquired immunity and may be more susceptible to infectious agents than are older cows. All but 8 of the 28 LSM differences between parities were significant $(P<0.05)$. The reason for the shift between phenotypic means and LSM is unknown. Some cows that abort during earlier lactations are culled (Peter, 2000). Thurmond et al. (1990b) reported that abortion rate was higher among cows that had experienced a previous abortion compared with those that had not. All causes of higher abortion frequencies for earlier parities are unknown, although parity differences in traits such as dystocia and stillbirth have been reported (VanTassell et al., 2003; Cole et al., 2007; Zaborski et al., 2009; Norman et al., 2010) and would be expected to have an effect on subsequent reproductive health. A contrasting result was found by Thurmond et al. (1990b), who reported that abortion rate increased after cows reached 5 yr of age, after 5 pregnancies, or after 4 calvings.

Table 4 shows phenotypic means and LSM for frequency of DHI-recorded abortions associated with pregnancy stage. Phenotypic means declined from $4.26 \%$ for early gestation (152-175 d) to $0.68 \%$ for late gestation (226-250 d). Abortion rates from LSM were similar at 4.38 and $0.59 \%$, respectively. All LSM differences between pregnancy stages were significant $(P<$ 0.001), and DHI-recorded abortion frequency declined steadily as gestation progressed. A decrease in abortion frequency from 201 to $230 \mathrm{~d}$ to 231 to $260 \mathrm{~d}$ was also reported by Forar et al. (1996). The chance of visually
Table 3. Numbers of lactations, phenotypic means, and LSM of frequency of DHI-recorded abortions by parity

\begin{tabular}{lccc}
\hline Parity & $\begin{array}{c}\text { Lactations, } \\
\text { no. }\end{array}$ & $\begin{array}{c}\text { Phenotypic } \\
\text { mean, } \%\end{array}$ & LSM, ${ }^{1} \%$ \\
\hline 1 & $3,336,905$ & 1.26 & 1.40 \\
2 & $2,359,776$ & 1.28 & 1.21 \\
3 & $1,423,107$ & 1.37 & 1.27 \\
4 & 752,946 & 1.41 & 1.29 \\
5 & 360,330 & 1.41 & 1.28 \\
6 & 158,592 & 1.41 & 1.25 \\
7 & 65,673 & 1.30 & 1.07 \\
$\geq 8$ & 38,962 & 1.25 & 1.01 \\
\hline
\end{tabular}

${ }^{1}$ All parities were significantly different $(P<0.05)$ except parities 2 and 6,3 and 4,3 and 5,3 and 6,4 and 5,4 and 6,5 and 6 , and 7 and 8 .

observing evidence of abortion increases throughout gestation, which suggests that actual differences likely were greater than those detected.

Although breed differences in the frequency of DHIrecorded abortions (Table 1$)$ were not significant $(P$ $\geq 0.01)$ in preliminary analyses of sample herds, they were significant $(P<0.001)$ for the full data set. Phenotypic mean for frequency of DHI-recorded abortions (Table 5) was smaller for Jerseys (1.08\%) than for Holsteins $(1.32 \%)$ and other breeds (1.26\%), and LSM were similar $(1.10 \%$ for Jerseys compared with $1.32 \%$ for Holsteins and $1.27 \%$ for other breeds). Differences in frequency of DHI-recorded abortions among lactation milk yield groups (high, medium, and low) within breed were significant $(P<0.01)$ for all 3 breed groups. Cows in the high yield group had higher abortion rates (LSM of 1.39 to $1.53 \%$ ) than did cows in the low group (0.76 to $0.98 \%)$. The historic trend for increased milk yield per cow (Animal Improvement Programs Laboratory, 2011b) may have contributed to more abortions over time. However, no significant difference $(P>0.10)$ was found for year in the full data set, which included lactations from 2001 through 2009.

Herd size differences in herd-year abortion means were nonsignificant $(P>0.05)$ and, therefore, are not shown. Because infectious agents are the most common cause of abortion for cows with a causative diagnosis (Jamaluddin et al., 1996; Khodakaram-Tafti and Ikede,

Table 4. Numbers of lactations, phenotypic means, and LSM of frequency of DHI-recorded abortions by pregnancy stage

\begin{tabular}{lccc}
\hline $\begin{array}{l}\text { Pregnancy } \\
\text { stage, }^{1} \mathrm{~d}\end{array}$ & $\begin{array}{c}\text { Lactations, } \\
\text { no. }\end{array}$ & $\begin{array}{c}\text { Phenotypic } \\
\text { mean, \% }\end{array}$ & LSM, $^{2} \%$ \\
\hline $152-175$ & 440,019 & 4.26 & 4.38 \\
$176-200$ & 728,119 & 3.13 & 3.27 \\
$201-225$ & $4,112,752$ & 1.16 & 1.19 \\
$226-250$ & $3,215,401$ & 0.68 & 0.59 \\
\hline
\end{tabular}

${ }^{1}$ Days from last insemination to last day milked.

${ }^{2}$ All pregnancy stages were significantly different $(P<0.001)$. 
Table 5. Numbers of lactations, phenotypic means, and LSM of frequency of DHI-recorded abortions by breed and lactation milk yield

\begin{tabular}{llccc}
\hline Breed & $\begin{array}{l}\text { Lactation } \\
\text { milk yield }\end{array}$ & $\begin{array}{c}\text { Lactations, } \\
\text { no. }\end{array}$ & $\begin{array}{c}\text { Phenotypic } \\
\text { mean, \% }\end{array}$ & LSM, $^{2} \%$ \\
\hline Holstein & High & $1,550,717$ & 1.40 & 1.53 \\
& Medium & $4,673,743$ & 1.32 & 1.35 \\
& Low & $1,550,694$ & 1.26 & 0.98 \\
Jersey & All cows & $7,775,154$ & 1.32 & 1.32 \\
& High & 107,720 & 1.17 & 1.23 \\
& Medium & 327,735 & 1.09 & 0.76 \\
Other breeds & Low & 107,725 & 0.97 & 1.10 \\
& All cows & 543,180 & 1.08 & 1.49 \\
& High & 34,244 & 1.30 & 1.30 \\
& Medium & 109,467 & 1.24 & 0.93 \\
& Low & 34,246 & 1.26 & 1.27 \\
\hline
\end{tabular}

${ }^{1}$ High $=$ top $20 \%$ of cows, medium $=$ middle $60 \%$, and low $=$ bottom $20 \%$ within each herd.

${ }^{2}$ Only Holsteins and Jerseys were significantly different $(P<0.01)$; all yield groups were significantly different $(P<0.01)$ within breed.

${ }^{3}$ Includes crossbred cows.

2005), cows in larger herds might have been expected to be at higher risk for infection. Herd size was significant $(P<0.001)$ when region was excluded from the model, which likely indicates confounding with region.

Results of regional analysis are shown in Table 6 . Phenotypic mean frequency of DHI-recorded abortions was lowest in the Midwest and Northeast (1.13\%) and highest in the Southwest (1.62\%). Corresponding LSM were $0.69 \%$ for the Northwest and $1.61 \%$ for the Southeast. The regions with the highest phenotypic means and LSM of DHI-recorded abortions were those that included states with the highest mean maximum temperatures regardless of relative humidity (St-Pierre et al., 2003). Fourteen of the 21 LSM differences between regions were significant $(P<0.05)$. For effects of region and state in which the herd was located (not shown), Florida (246 herd-years) had the highest frequency of DHI-recorded abortions (1.96\%), and Oregon (531 herd-years) had the lowest $(0.90 \%)$.

Figure 1 shows the risk of an abortion for a cow in milk by pregnancy stage and by lactation stage. As expected, the risk of embryo loss on any particular day pregnant was low (0.01 to $0.14 \%$ ) but increased as gestation progressed from 152 to $250 \mathrm{~d}$, particularly after $215 \mathrm{~d}$ (Figure 1a). However, the actual frequency of abortions decreased as gestation progressed because fewer cows remained in milk. The abortion risk for a cow in milk for a given DIM (Figure 1b) was also low (0.01 to $0.04 \%)$ but increased as lactation progressed from 180 to $900 \mathrm{~d}$. Similar to the situation for gestation stage, the actual frequency of abortions decreased as DIM increased because fewer cows had extended lactations.

When DIM was added to the model, LSM (Table 7) declined sharply as pregnancy and lactation pro- gressed together. Within DIM group, all LSM differences between pregnancy stages were significant $(P$ $<0.01$, with 29 of 30 also significant at $P<0.001$ ). Within pregnancy stage group, 32 of 40 LSM differences between DIM group were significant $(P<0.05$, with 28 of 40 significant at $P<0.001)$. For the earliest pregnancy-lactation stage combination, LSM for abortion frequency was $8.14 \%$ in contrast to $0.43 \%$ for the latest pregnancy-lactation stage combination.

Numbers of matings used to determine time of fetal loss during gestation based on NRR at 60 to $200 \mathrm{~d}$ and

Table 6. Numbers of herd-years, phenotypic means, and LSM of frequency of recorded abortions by US region

\begin{tabular}{lccc}
\hline & $\begin{array}{c}\text { Herd-years, } \\
\text { Region }\end{array}$ & $\begin{array}{c}\text { Phenotypic } \\
\text { mean, \% }\end{array}$ & LSM, $^{2} \%$ \\
\hline Mideast & 4,147 & 1.47 & 1.20 \\
Midwest & 18,789 & 1.13 & 1.31 \\
Mountain/Prairie & 2,387 & 1.44 & 1.37 \\
Northeast & 13,077 & 1.13 & 1.04 \\
Northwest & 2,176 & 1.18 & 0.69 \\
Southeast & 2,549 & 1.52 & 1.61 \\
Southwest & 3,001 & 1.62 & 1.55 \\
\hline
\end{tabular}

${ }^{1}$ Mideast $=$ Delaware, Kentucky, Maryland, North Carolina, Tennessee, Virginia, and West Virginia; Midwest = Illinois, Indiana, Iowa, Michigan, Minnesota, Missouri, Ohio, and Wisconsin; Mountain/ Prairie = Colorado, Kansas, Montana, Nebraska, North Dakota, South Dakota, Utah, and Wyoming; Northeast = Connecticut, Maine, Massachusetts, New Hampshire, New Jersey, New York, Pennsylvania, Rhode Island, and Vermont; Northwest = Alaska, Idaho, Oregon, and Washington; Southeast = Alabama, Arkansas, Florida, Georgia, Louisiana, Mississippi, Oklahoma, Puerto Rico, South Carolina, and Texas; and Southwest = Arizona, California, Hawaii, Nevada, and New Mexico.

${ }^{2}$ All regions were significantly different $(P<0.05)$ except for Mideast and Southeast, Mideast and Southwest, Midwest and Northeast, Mountain/Prairie and Northeast, Mountain/Prairie and Southwest, Northeast and Northwest, and Southeast and Southwest. 

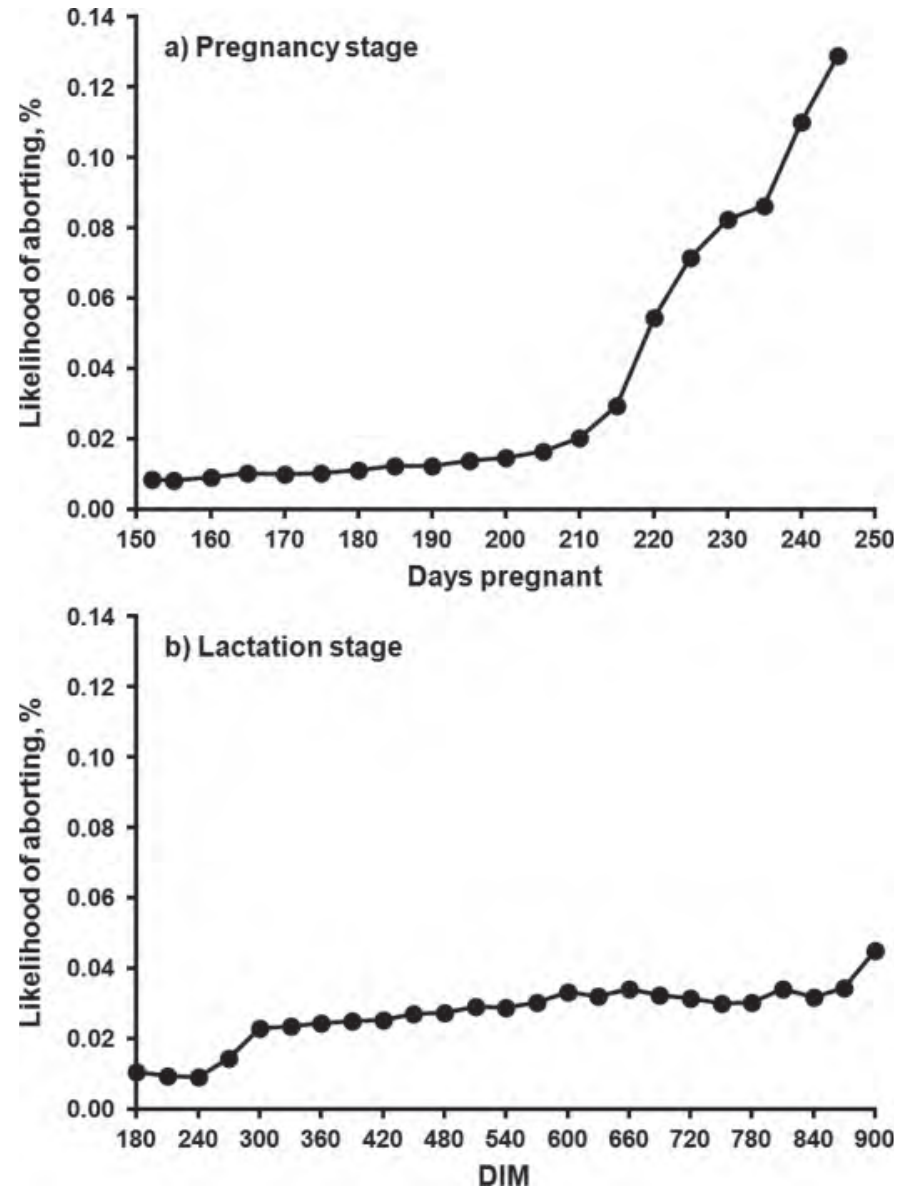

Figure 1. Risk of an abortion for a cow in milk on a given day by (a) pregnancy stage, and (b) lactation stage for cows pregnant $\geq 152 \mathrm{~d}$.

SCR are in Table 8 for several known undesirable recessives. For Holsteins, a total of 12,459,038 to 14,371,592 matings were examined for BY, CVM, HH1, HH2, and HH3; of those, 3,252 to 27,535 had both carrier service sire and carrier cow sire. For Brown Swiss BH1, 989 of 61,888 to 61,919 matings for NRR and 936 of 58,229 matings for SCR had a carrier service sire and carrier cow sire; corresponding numbers for Jersey JH1 were 55,654 to 55,693 of 673,079 to 673,831 matings for NRR and 52,449 of 626,558 matings for SCR.

For each of the undesirable recessives, Table 9 shows the difference between matings with a noncarrier service sire and those with a carrier service sire and carrier cow sire for NRR calculated for 8 periods of delay after insemination and for SCR. Comparison of the carrier status difference for NRR at $100 \mathrm{~d}$ with the difference for SCR showed that $86 \%(2.35 / 2.72)$ of fertility loss associated with BY occurred by $100 \mathrm{~d}$ after breeding, an earlier loss than estimated by Georges et al. (2010). For fertility loss associated with CVM, only $40 \%(0.97 / 2.42)$ occurred by $60 \mathrm{~d}$ after breeding,
$51 \%(1.24 / 2.42)$ by $100 \mathrm{~d}$, and $66 \%(1.59 / 2.42)$ by 140 $\mathrm{d}$, which was relatively consistent with the results of Berglund et al. (2004). For HH1, 34\% (0.96/2.83) of associated fertility loss occurred by $60 \mathrm{~d}$ after breeding, $51 \%(1.43 / 2.83)$ by $100 \mathrm{~d}$, and $63 \%(1.78 / 2.83)$ by 140 d. For HH2, 56\% (2.50/4.44) of associated fertility loss occurred by $60 \mathrm{~d}$ after breeding and $94 \%$ (4.16/4.44) by 100 d. For HH3, $93 \%$ (2.71/2.91) of associated fertility loss occurred by $60 \mathrm{~d}$ after breeding. For JH1, all associated pregnancy failure occurred by $60 \mathrm{~d}$ after breeding $(3.73 / 3.63)$. For BH1, most fertility loss appeared to occur by $80 \mathrm{~d}$ pregnant; however, Brown Swiss differences were somewhat erratic, likely because of the much smaller numbers of matings (Table 8). Standard errors of differences also are shown in Table 9. Comparison of early NRR with 200-d NRR instead of SCR (not shown) produced similar results.

The undesirable recessives were associated with only a very small proportion of DHI-recorded abortions (Table 10). For example, JH1 had the highest carrier frequency $(20.7 \%)$. Therefore, only $1.07 \%\left[0.25\left(0.207^{2}\right)\right]$ of random Jersey matings would be expected to result in fertility loss because of JH1. However, based on the carrier status differences in Table 9, none of the reduction in NRR associated with JH1 occurred after $60 \mathrm{~d}$ following insemination. Thus, JH1 was not associated with DHI-recorded abortions, which occurred from 152 to $250 \mathrm{~d}$ of gestation. The BH1 haplotype had the next largest carrier frequency $(16.3 \%)$, and $0.66 \%$ of random matings were expected to result in fertility loss (Table 10). Again, based on carrier status differences in Table 9 , only $2.2 \%(1-\{[(3.21+2.97) / 2] / 3.16\})$ of fertility loss from BH1 was expected between 152 and $250 \mathrm{~d}$ of gestation, and only $0.015 \%$ [0.022(0.66)] of the fertility loss from random matings would have occurred then (Table 10). Based on an LSM of $1.27 \%$ for frequency of DHI-recorded abortions for breeds other than Holstein and Jersey (Table 5), only 1.2\% (0.015/1.27) of abortions could have been associated with BH1. The 5 Holstein recessives sum to an expected fertility loss of $0.29 \%$ for random matings, but a smaller percentage $(0.033 \%)$ of those matings would be expected to contribute to fertility loss between 152 and $250 \mathrm{~d}$ pregnant. For CVM and BY, 33.7 and $11.4 \%$, respectively, of the reduction in NRR occurred after 152 d pregnant. For Holstein recessive haplotypes, the corresponding reduction in NRR was $30.2 \%$ for $\mathrm{HH} 1,9.7 \%$ for $\mathrm{HH} 2$, and $0.0 \%$ for HH3. Overall association of Holstein recessives with DHI-recorded abortions was $2.4 \%$ ( $0.7 \%$ for BY, $0.6 \%$ for CVM, $0.4 \%$ for $\mathrm{HH} 1,0.7 \%$ for $\mathrm{HH} 2$, and $0.0 \%$ for HH3). The extremely small percentages $(0.0$ to $1.2 \%$ ) of DHI-recorded abortions that could be associated with undesirable recessives indicate that differences in DHI-recorded abortion rates between months, 
Table 7. Numbers of lactations, phenotypic means, and LSM of DHI-recorded abortions by pregnancy stage and lactation stage

\begin{tabular}{|c|c|c|c|c|}
\hline $\begin{array}{l}\text { Pregnancy } \\
\text { stage, }{ }^{1} \mathrm{~d}\end{array}$ & $\begin{array}{l}\text { Lactation } \\
\text { stage, DIM }\end{array}$ & $\begin{array}{c}\text { Lactations, } \\
\text { no. }\end{array}$ & $\begin{array}{c}\text { Phenotypic } \\
\text { mean, \% }\end{array}$ & $\mathrm{LSM}^{2} \%$ \\
\hline \multirow[t]{5}{*}{$152-175$} & $<250$ & 65,307 & 7.90 & $8.14^{\mathrm{a}}$ \\
\hline & $250-349$ & 162,510 & 4.99 & $5.28^{\mathrm{b}}$ \\
\hline & $350-449$ & 120,580 & 2.83 & $2.98^{\mathrm{c}}$ \\
\hline & $450-549$ & 60,063 & 2.27 & $2.25^{\mathrm{d}}$ \\
\hline & 550-999 & 31,559 & 2.20 & $2.04^{\mathrm{e}}$ \\
\hline \multirow[t]{5}{*}{$176-200$} & $<250$ & 37,434 & 5.93 & $6.31^{\mathrm{a}}$ \\
\hline & $250-349$ & 323,786 & 3.86 & $4.18^{\mathrm{b}}$ \\
\hline & $350-449$ & 219,372 & 2.33 & $2.48^{\mathrm{c}}$ \\
\hline & $450-549$ & 99,097 & 2.01 & $1.97^{\mathrm{d}}$ \\
\hline & 550-999 & 48,430 & 1.93 & $1.78^{\mathrm{e}}$ \\
\hline \multirow[t]{5}{*}{$201-225$} & $<250$ & 14,694 & 2.20 & $2.56^{\mathrm{a}}$ \\
\hline & $250-349$ & $2,452,420$ & 1.19 & $1.28^{\mathrm{b}}$ \\
\hline & $350-449$ & $1,161,543$ & 1.10 & $1.09^{c}$ \\
\hline & $450-549$ & 352,231 & 1.11 & $0.99^{\mathrm{d}}$ \\
\hline & 550-999 & 131,864 & 1.22 & $1.03^{\mathrm{cd}}$ \\
\hline \multirow[t]{5}{*}{$226-250$} & $<250$ & 522 & 0.77 & $0.81^{\mathrm{a}}$ \\
\hline & $250-349$ & $1,869,259$ & 0.67 & $0.59^{\mathrm{a}}$ \\
\hline & $350-449$ & 994,551 & 0.68 & $0.53^{\mathrm{ab}}$ \\
\hline & $450-549$ & 257,867 & 0.72 & $0.49^{\mathrm{abc}}$ \\
\hline & 550-999 & 93,202 & 0.71 & $0.43^{\mathrm{ac}}$ \\
\hline
\end{tabular}

parities, pregnancy stages, or regions are not primarily caused by those recessives.

\section{CONCLUSIONS}

From 2001 through 2009, frequency of DHI-recorded abortions was $1.31 \%$ for 8.5 million lactations of cows that were $\geq 152 \mathrm{~d}$ pregnant at lactation termination. Spring and summer may favor the spread of infectious agents that cause abortion, as recorded abortions were most frequent from May through August and least frequent from October through February. Younger cows had more lactations coded as ending with an abortion than older cows. Recorded abortions were more frequent early in gestation; frequency at 152 to 175 d pregnant was 3.79 percentage points higher than at 226 to 250 d. Frequency of DHI-recorded abortions also increased as lactation milk yield increased; frequency for the top $20 \%$ of lactations for milk yield was 0.55 to 0.63 percentage points higher than for the bottom $20 \%$. Jerseys had a slightly lower frequency $(1.10 \%)$ for DHI-recorded abortions than did other breeds (1.27 to $1.32 \%)$. The highest frequency geographically for DHIrecorded abortions was in the Southeast region $(1.61 \%)$ and the lowest was in the Northwest region (0.69\%). The recorded incidence of abortion in DHI herds underestimates the true incidence because of failure to observe physical evidence. In addition, herds differ in the completeness and accuracy of their records. How- ever, recorded abortions in DHI herds should provide a reasonable indication when analyzed within herd of the relative importance of the same effects on true abortion frequency in those herds. Nonreturn rate was used to show when pregnancy loss occurred even if abortions were not recorded before $152 \mathrm{~d}$ pregnant. Over $80 \%$ of pregnancy failure was found by $60 \mathrm{~d}$ after breeding for BH1, HH3, and JH1; by 80 d for HH2; by 100 d for BY; and by $180 \mathrm{~d}$ for HH1. For CVM, possible associated fertility loss increased gradually from 40 to $74 \%$ across the entire gestation. The known undesirable recessives for fertility had only a small effect on overall abortion rate recorded through DHI.

\section{ACKNOWLEDGMENTS}

The Council on Dairy Cattle Breeding and its member organizations contributed genotypes, phenotypes, and pedigrees used in this research. The Bovine Functional Genomic Laboratory (ARS, USDA; Beltsville, MD) and private breeders contributed genotypes and DNA from early ancestors that made inheritance of the defects easier to trace. The cooperation of the dairy records processing centers (AgriTech Analytics, Visalia, CA; AgSource Cooperative Services, Verona, WI; DHI Computing Service, Provo, UT; and Dairy Records Management Systems, Raleigh, NC, and Ames, IA) in supplying lactation records is acknowledged. The valuable assistance of P. M. VanRaden and S. M. Hub- 
Table 8. Numbers of matings based on service sire and cow sire carrier status for brachyspina (BY), complex vertebral malformation (CVM), or an undesirable recessive haplotype ${ }^{1}$ for fertility by nonreturn rate (NRR) and sire conception rate (SCR)

NRR

\begin{tabular}{|c|c|c|c|c|c|c|c|c|c|c|}
\hline Mating carrier status & Recessive & $60 \mathrm{~d}$ & $80 \mathrm{~d}$ & $100 \mathrm{~d}$ & $120 \mathrm{~d}$ & $140 \mathrm{~d}$ & $160 \mathrm{~d}$ & $180 \mathrm{~d}$ & $200 \mathrm{~d}$ & SCR \\
\hline \multirow{7}{*}{$\begin{array}{l}\text { Carrier service sire and } \\
\text { carrier cow sire }\end{array}$} & BH1 & 989 & 989 & 989 & 989 & 989 & 989 & 989 & 989 & 936 \\
\hline & BY & 27,530 & 27,532 & 27,531 & 27,534 & 27,533 & 27,535 & 27,535 & 27,535 & 26,143 \\
\hline & CVM & 9,859 & 9,861 & 9,861 & 9,862 & 9,863 & 9,863 & 9,863 & 9,863 & 9,387 \\
\hline & HH1 & 25,873 & 25,882 & 25,882 & 25,881 & 25,882 & 25,882 & 25,883 & 25,883 & 24,554 \\
\hline & HH2 & 3,441 & 3,442 & 3,442 & 3,444 & 3,444 & 3,444 & 3,444 & 3,444 & 3,252 \\
\hline & HH3 & 14,968 & 14,970 & 14,972 & 14,972 & 14,973 & 14,972 & 14,972 & 14,972 & 14,114 \\
\hline & JH1 & 55,654 & 55,683 & 55,691 & 55,693 & 55,693 & 55,693 & 55,693 & 55,693 & 52,449 \\
\hline \multirow[t]{7}{*}{ Noncarrier service sire } & BH1 & 60,899 & 60,930 & 60,929 & 60,925 & 60,929 & 60,925 & 60,925 & 60,925 & 57,293 \\
\hline & BY & $14,063,867$ & $14,067,596$ & $14,068,278$ & $14,068,684$ & $14,069,354$ & $14,070,192$ & $14,070,526$ & $14,070,839$ & $13,320,846$ \\
\hline & CVM & $13,208,467$ & $13,212,292$ & $13,212,995$ & $13,213,407$ & $13,214,072$ & $13,214,953$ & $13,215,292$ & $13,215,590$ & $12,449,651$ \\
\hline & HH1 & $14,161,144$ & $14,164,774$ & $14,165,401$ & $14,165,785$ & $14,166,466$ & $14,167,337$ & $14,167,637$ & $14,167,943$ & $13,414,266$ \\
\hline & HH2 & $14,361,135$ & $14,364,947$ & $14,365,614$ & $14,366,019$ & $14,366,663$ & $14,367,517$ & $14,367,831$ & $14,368,148$ & $13,607,680$ \\
\hline & HH3 & $14,275,602$ & $14,279,354$ & $14,280,028$ & $14,280,431$ & $14,281,117$ & $14,281,994$ & $14,282,298$ & $14,282,614$ & $13,529,474$ \\
\hline & JH1 & 617,425 & 617,764 & 618,048 & 618,087 & 618,137 & 618,138 & 618,137 & 618,122 & 574,109 \\
\hline
\end{tabular}

${ }^{1}$ Brown Swiss BH1; Holstein HH1, HH2, and HH3; and Jersey JH1 (VanRaden et al., 2011b). NRR 
Table 10. Relationship of brachyspina (BY), complex vertebral malformation (CVM), and an undesirable recessive haplotype ${ }^{1}$ for fertility to DHI-recorded abortions

\begin{tabular}{lccccc}
\hline & & \multicolumn{4}{c}{ Expected fertility loss, \% } \\
\cline { 3 - 5 } Recessive & $\begin{array}{c}\text { Carrier } \\
\text { frequency, } \%\end{array}$ & $\begin{array}{c}\text { Random } \\
\text { mating }^{2}\end{array}$ & $\begin{array}{c}152 \text { to 250 d } \\
\text { pregnant }^{3}\end{array}$ & $\begin{array}{c}\text { 152 to 250 d pregnant } \\
\text { after random mating }\end{array}$ & $\begin{array}{c}\text { Possible association } \\
\text { with DHI-recorded } \\
\text { abortion, }\end{array}$ \\
\hline BH1 & 16.3 & 0.66 & 2.2 & 0.015 & 0.009 \\
BY & 5.6 & 0.08 & 11.4 & 0.008 & 0.006 \\
CVM & 3.1 & 0.02 & 33.7 & 0.010 & 0.7 \\
HH1 & 2.7 & 0.02 & 30.2 & 0.000 & 0.4 \\
HH2 & 6.4 & 0.10 & 9.6 & 0.000 & 0.7 \\
HH3 & 5.2 & 0.07 & 0.0 & 0.0 & 0.0 \\
JH1 & 20.7 & 1.07 & 0.0 & \\
\hline
\end{tabular}

${ }^{1}$ Brown Swiss BH1; Holstein HH1, HH2, and HH3; and Jersey JH1 (VanRaden et al., 2011b).

${ }^{2}$ Expected fertility loss $=0.25$ (square of carrier frequency).

${ }^{3}$ Expected fertility loss $=100\{1-[($ carrier status difference for nonreturn rate at $150 \mathrm{~d}) /($ carrier status difference for sire conception rate $)]\}$, where carrier status difference was matings with a noncarrier service sire minus matings with a carrier service sire and carrier cow sire, difference for 150-d nonreturn rate was the mean of 140 and $160 \mathrm{~d}$ differences in Table 9, and difference for sire conception rate was reported in Table 9. ${ }^{4}$ Expected fertility loss at 152 to $250 \mathrm{~d}$ pregnant after a random mating times breed LSM in Table 5.

bard of the Animal Improvement Programs Laboratory (Beltsville, MD) in manuscript preparation and review is greatly appreciated.

\section{REFERENCES}

Agerholm, J. S., C. Bendixen, O. Andersen, and J. Arnbjerg. 2001. Complex vertebral malformation in Holstein calves. J. Vet. Diagn. Invest. 13:283-289.

Agerholm, J. S., and K. Peperkamp. 2007. Familial occurrence of Danish and Dutch cases of the bovine brachyspina syndrome. BMC Vet. Res. 3:8

American Dairy Science Association. 1941. Rules for the herd improvement registry test. J. Dairy Sci. 24:463-465.

Animal Improvement Programs Laboratory. 2011a. List of reference notes for format 4 as of: 2011-09-01. Accessed Sep. 22, 2011. http://aipl.arsusda.gov/CF-RCS/GetAllRef.cfm?docname=fmt4. html\&format=fmt $4 \&$ title=List of Reference Notes for Format $4 \&$ NextChangeDate $=2011-09-01$.

Animal Improvement Programs Laboratory. 2011b. Trend in milk BV for Holstein or Red \& White. Accessed Sep. 22, 2011. http://aipl. arsusda.gov/eval/summary/trend.cfm.

Berglund, B., A. Persson, and H. Stålhammar. 2004. Effects of complex vertebral malformation on fertility in Swedish Holstein cattle. Acta Vet. Scand. 45:161-165.

Carpenter, T. E., M. Chrièl, M. M. Andersen, L. Wulfson, A. M. Jensen, H. Houe, and M. Greiner. 2006. An epidemiologic study of late-term abortion in dairy cattle in Denmark, July 2000-August 2003. Prev. Vet. Med. 77:215-229.

Cole, J. B., G. R. Wiggans, and P. M. VanRaden. 2007. Genetic evaluation of stillbirth in United States Holsteins using sire-maternal grandsire threshold model. J. Dairy Sci. 90:2480-2488.

De Vries, A. 2006. Economic value of pregnancy in dairy cattle. J. Dairy Sci. 89:3876-3885.

Ettema, J. F., and J. E. P. Santos. 2004. Impact of age at calving on lactation, reproduction, health, and income in first-parity Holsteins on commercial farms. J. Dairy Sci. 87:2730-2742.

Fetrow, J., K. V. Nordlund, and H. D. Norman. 2006. Invited review: Culling: Nomenclature, definitions, and recommendations. J. Dairy Sci. 89:1896-1905.

Forar, A. L., J. M. Gay, and D. D. Hancock. 1995. The frequency of endemic fetal loss in dairy cattle: A review. Theriogenology 43:989-1000
Forar, A. L., J. W. Gay, D. D. Hancock, and C. C. Gay. 1996. Fetal loss frequency in ten Holstein dairy herds. Theriogenology 45:1505-1513.

Georges, M., W. Coppieters, C. Charlier, J. S. Agerholm, and M. Fredholm, inventors. 2010. A genetic marker test for brachyspina and fertility in cattle. Int. Patent Pub. No. WO2010/012690.

Hanson, T., E. J. Bedrick, W. O. Johnson, and M. C. Thurmond. 2003. A mixture model for bovine abortion and foetal survival. Stat. Med. 22:1725-1739.

Hare, E., H. D. Norman, and J. R. Wright. 2004. Duration of herd participation in Dairy Herd Improvement milk recording in the United States. J. Dairy Sci. 87:2743-2747.

Holstein Association USA. 2011. Holstein Association USA board holds spring meeting. Holstein Pulse (Spring). Holstein Association USA, Brattleboro, VT.

Hovingh, E. 2009. Abortions in dairy cattle: I. Common causes of abortions. Virginia Coop. Ext. Publ. 404-288. Virginia Polytechnic Institute and State University, Blacksburg.

Jamaluddin, A. A., J. T. Case, D. W. Hird, P. C. Blanchard, J. R. Peauroi, and M. L. Anderson. 1996. Dairy cattle abortion in California: Evaluation of diagnostic laboratory data. J. Vet. Diagn. Invest. 8:210-218.

Khodakaram-Tafti, A., and B. O. Ikede. 2005. A retrospective study of sporadic bovine abortions, stillbirths, and neonatal abnormalities in Atlantic Canada, from 1990 to 2001. Can. Vet. J. 46:635-637.

Kinsel, M. L. 1999. An epidemiological approach to investigating abortion problems in dairy herds. Bovine Proc. 32:152-160.

Kirk, J. H. 2003. Infectious abortions in dairy cows. Vet. Med. Ext. Fact Sheet, Univ. of California, Davis. Accessed Sep. 21, 2011. http://www.vetmed.ucdavis.edu/vetext/INF-DA/Abortion.pdf.

Kuhn, M. T., and J. L. Hutchison. 2008. Prediction of dairy bull fertility from field data: Use of multiple services and identification and utilization of factors affecting bull fertility. J. Dairy Sci. 91:2481-2492

Misztal, I. 2011. BLUPF90 family of programs. Accessed Dec. 29, 2011. http://nce.ads.uga.edu/ ignacy/newprograms.html.

Moller, K., P. E. Newling, H. J. Robson, G. J. Jansen, and J. A. Meursinge. 1967. A survey of abortions and long return intervals in dairy herds in the Huntly district. N. Z. Vet. J. 15:137-142.

Murray, R. D. 1990. A field investigation of causes of abortion in dairy cattle. Vet. Rec. 127:543-547.

National DHIA. 2002. Uniform data collection procedures. Accessed Sep. 22, 2011. http://www.dhia.org/udcp.pdf.

Nielen, M., Y. H. Schukken, D. T. Scholl, H. J. Wilbrink, and A. Brand. 1989. Twinning in dairy cattle: A study of risk factors and effects. Theriogenology 32:845-862. 
Norman, H. D., J. L. Hutchison, and R. H. Miller. 2010. Use of sexed semen and its effect on conception rate, calf sex, dystocia, and stillbirth of Holsteins in the United States. J. Dairy Sci. 93:38803890.

Norman, H. D., J. L. Hutchison, and J. R. Wright. 2008. Sire conception rate: New national AI bull fertility evaluation. AIPL Res. Rep. SCR1(7-08). Accessed Sep. 27, 2011. http://aipl.arsusda. gov/reference/arr-scr1.htm.

Norman, H. D., J. R. Wright, S. M. Hubbard, R. H. Miller, and J. L. Hutchison. 2009. Reproductive status of Holstein and Jersey cows in the United States. J. Dairy Sci. 92:3517-3528.

Peter, A. T. 2000. Abortions in dairy cows: New insights and economic impact. Adv. Dairy Technol. 12:233-244.

Pitel, P.-H., S. Pronost, G. Chatagnon, D. Tainturier, G. Fortier, and J.-J. Ballet. 2001. Neosporosis in bovine dairy herds from the west of France: Detection of Neospora caninum DNA in aborted fetuses, seroepidemiology of $N$. caninum in cattle and dogs. Vet. Parasitol. 102:269-277.

Risco, C. A., G. A. Donovan, and J. Hernandez. 1999. Clinical mastitis associated with abortion in dairy cows. J. Dairy Sci. 82:16841689 .

Santos, J. E. P., S. O. Juchem, K. N. Galvão, and R. L. A. Cerri. 2003. Transition cow management to reduce metabolic diseases and improve reproductive management. Adv. Dairy Technol. $15: 287-305$.

SAS Institute. 2004. SAS OnlineDoc 9.1.2. Accessed Sep. 22, 2011. http://support.sas.com/onlinedoc/912/.

Sattler, C. G. 2002. Update on CVM research. Pages 19-22 in Proc. 19th Tech. Conf. AI Reprod. Natl. Assoc. Anim. Breeders, Columbia, MO.
Schutz, M. M. 1994. Age-season standardization for yield traits. Accessed Sep. 22, 2011. http://aipl.arsusda.gov/reference/ageseason. htm.

St-Pierre, N. R., B. Cobanov, and G. Schnitkey. 2003. Economic losses from heat stress by US livestock industries. J. Dairy Sci. 86(E Suppl.):E52-E77.

Thurmond, M. C., J. P. Picanso, and S. K. Hietala. 1990a. Prospective serology and analysis in diagnosis of dairy cow abortion. J. Vet. Diagn. Invest. 2:274-282.

Thurmond, M. C., J. P. Picanso, and C. M. Jameson. 1990b. Special report: Considerations for use of descriptive epidemiology to investigate fetal loss in dairy cows. J. Am. Vet. Med. Assoc. 197:1305-1312.

Van Tassell, C. P., G. R. Wiggans, and I. Misztal. 2003. Implementation of a sire-maternal grandsire model for evaluation of calving ease in the United States. J. Dairy Sci. 86:3366-3373.

VanRaden, P. M., D. J. Null, K. M. Olson, and J. L. Hutchison. 2011a. Reporting of haplotypes with recessive effects on fertility. 2011 Interbull Bull. 44. Accessed Sep. 22, 2011. http://www.interbull. org/images/stories/Vanraden_copy_copy.pdf.

VanRaden, P. M., K. M. Olson, D. J. Null, and J. L. Hutchison. 2011b. Harmful recessive effects on fertility detected by absence of homozygous haplotypes. J. Dairy Sci. 94:6153-6161.

Zaborski, D., W. Grzesiak, I. Szatkowska, A. Dybus, M. Muszynska, and M. Jedrzejczak. 2009. Factors affecting dystocia in cattle. Reprod. Domest. Anim. 44:540-551. 